\title{
STOCHASTIC PROCESSES IN PROJECT MANAGEMENT
}

\author{
Nataliia Oberemok \\ Department of Technology Management \\ Taras Shevchenko National University of Kyiv \\ 60 Volodymyrska str., Kyiv, Ukraine, 01033 \\ oberemokn@gmail.com \\ Ivan Oberemok \\ Department of Project Management \\ Kiev National University of Construction and Architecture \\ 3 Povitroflotskyi ave., Kyiv, Ukraine, 03037 \\ oberemokii@gmail.com
}

\begin{abstract}
Performance of planned activities not always leads to the achievement of planned results in innovation projects with a high degree of uncertainty. Management of such specific projects requires the usage of specific methods and processes. It is necessary to develop own stochastic process methods rather than use classical methods of deterministic management.

The main peculiarity of stochastic processes of projects consists in the inability to carry out more than one experiment. Implementation of a project is a stochastic process, which is carried out only once.

For the purposes of the research, stochastic project management is the process of organisation, planning and control over projects, in which the decisions and actions of managers are described by stochastic functions. If the project realisation is described by stochastic processes, the project management process is indeed described by stochastic processes.

This research suggests a project management approach based on the focus on the project product and project management as stochastic processes based on stochastic functions. It is demonstrated that stochastic function values, which underlie the stochastic processes, are formed by the intellectual instruments of those involved in the project and are developed on the basis of their knowledge and skills. The latter, in turn, are the result of studying and practical work on the project. Therefore, it is difficult to predict decisions and actions of managers and contractors, even if internal and external influences on them are specified. Then, any decisions or actions of such persons with regard to the external observer are described by stochastic functions.

The purpose of this study is to describe the processes of stochastic project management. The purpose of the study is the project management process. The subject of research is the methods of stochastic project management. Within the framework of the study, all groups of processes of stochastic control will be mathematically described and the conditions of their impact determined.

The processes of stochastic project management are outlined and formally presented. These are the processes of project management organisation, the processes of project management support, processes of project content definition, processes of defining the resources, required for the project works, processes of project planning, processes of influence on contractors of actions (works).

Keywords: project product, project management processes, stochastic processes, project management.
\end{abstract}

\section{Introduction}

All projects are aimed at receiving a product. Product receipt is aligned to both the interaction within the project environment and the influence of its outer environment.

The project product is a result of the work being done in the project processes. The work itself is considered as determined. It is believed that any well-organised and realised work always produces required results, given that the resources are specified [1]. However, this situation might be different in the case of innovation commercial projects. Some works might not lead to the planned results [2].

As for instance, geological prospecting project. For such projects it is quite difficult to foresee their content, results and duration, as far as geological projects carry uncertainty, many changes and risks. In addition, such projects are invariant. They can be performed differently and different decision can be made as to their organisation, planning, place of realisation etc. Therefore, even under the same initial conditions the realisation of such projects might be different [3]. An outside 
observer sees the implementation of such projects as a set of processes, in which the actions of managers and contractors look differently and stochastically with different probability.

Decision making in projects based on the wishes of strategies has become a global trend. Project managers build processes and select management approaches based on the opinions of strategies [4]. This approach is ineffective with the rapid change in the wishes of strategies.

Creating decision-making systems based on the values of stakeholders is not a new idea [5]. At the same time, dynamic restructuring of the processes of value formation is possible only when using stochastic control processes.

Geological projects are a common name for several separate types of projects that are part of the general development of the territory. For each type of project portfolio and portfolio, its own rules of management should be defined [6]. Which greatly complicates the company's project management system. At the same time, the linear planning and management process does not ensure timely implementation of external events [7].

The management of such specific projects requires the usage of specific methods. Own process stochastic methods should be developed rather than classical approaches of deterministic management.

The main peculiarity of stochastic processes is that it is impossible to conduct more than one experiment. Realization of any project is a stochastic process, which is carried out only once. Therefore, the probability of retrieving any values in stochastic functions is impossible to measure from the standpoint of an observer. However, it is understood through insight that those values are stochastic. And even under the same conditions in such other project the values of actions, resources and management will be other. Then how to measure the probability of values of stochastic functions? With it being done not from the outside perspective of the observer of the repeated experiments, but from the inside, when the actions of those forming the values of stochastic functions (project team) can be presented through the probabilities which represent the statistics of previously taken decisions in the similar project situations or through the subjective probabilities. The probabilities refer to the probabilities of taking decisions by the project team members. It involves the stochastic processes in project management in the work of the project team.

The approaches developed within the framework of the theory of non-force interaction [8] allow us to develop stochastic processes within the framework of project management. The approaches and methods developed in the framework of the theory of non-force interaction have proven themselves in solving managerial problems [9].

\section{Aim of research}

The purpose of this research is to define and describe the processes of stochastic project management.

\section{Methods}

Objectives of the study:

1. To determine the list of groups of processes required for the stochastic management of the projects.

2. Mathematically describe each group of processes and elements necessary for their implementation.

3. Determine the working conditions of each group of processes and ensure their joint work.

The stochastic project management refers to the processes of organisation, planning and control of projects, where the decisions and actions of managers and contractors are described by stochastic functions [10].

In developing processes, the methods of generalization and the method of system analysis were used. The generalization method was used to group different processes depending on the elements necessary for their implementation. The system analysis method was used to build a model of dependencies between different types of processes. The method of system analysis for the exact formulation of the elements was used in the implementation of various types of processes. 
If the project realization is described by the stochastic processes, the project management process is indeed described by the stochastic processes. These processes include:

- processes of project management organisation;

- processes of project management support;

- processes of project content definition;

- processes of the definition of resources required for the project works;

- processes of project planning;

- processes of influencing the contractors of actions (works).

\section{1. Processes of project management organisation}

The processes of project management organisation are aimed at the creation of the organisation support of project management processes. First of all, it is the creation of an organizational management structure, the establishment of its communication with senior management and functional management, and the management of the stakeholders [11]. It can be presented as follows:

$$
\mathrm{O}^{\mathrm{Y}}=\xi_{\mathrm{O}}^{\mathrm{Y}}\left(\mathrm{Z}, \mathrm{R}^{\mathrm{T}}, \mathrm{K}, \mathrm{M}\right)
$$

where $\mathrm{O}^{\mathrm{Y}}$ - organizational management structure; $\xi_{\mathrm{O}}^{\mathrm{Y}}(\ldots)$ - stochastic function, which defines the organizational structure; $\mathrm{Z}$ - documentation; $\mathrm{R}^{\mathrm{T}}$ - workforce; $\mathrm{K}$ - project objectives and environment; $\mathrm{M}$ - permanent organisation.

Definition 1. The stochastic function $\left(\xi_{\mathrm{O}}^{\mathrm{Y}}(\ldots)\right)$ is a function of creating the organisational structure of project management. Based on the objectives of the project and the conditions of its implementation, created by the company, it forms an organizational model, a matrix of responsibility, role functions, a system of interactions in project management.

Under the same initial conditions, the organisational structure will be different, as far as it depends, in the first place, on the vision and experience of the leadership of a permanent organization. Therefore, the processes of constructing the organizational structure of the project are stochastic.

These influences lead to the formation of:

- organizational role structure;

- role functions in the project team;

- project management unit;

- system of interaction with the senior management and the functional management.

\section{2. Processes of project management support}

The processes of project management support are generally realised separately from the processes of managing the creation of a project product. They are directed not alone at the creation of support systems, but at the realization of auxiliary management functions, such as procurement management, risk management, human resources management, information communications, quality management, stakeholder management.

The stochastic function displays the dependence between the informational environment of the project and such organisational, technological, financial and other measures, which allow for effective project management:

$$
\mathrm{B}^{\mathrm{Y}}=\xi_{\mathrm{B}}^{\mathrm{Y}}\left(\mathrm{O}^{\mathrm{Y}}, \mathrm{Z}, \mathrm{R}, \mathrm{U}, \mathrm{M}\right)
$$

where $\mathrm{B}^{\mathrm{Y}}$ - types of support required for project management; $\xi_{\mathrm{B}}^{\mathrm{Y}}(\ldots)$ - stochastic function, which defines the types of support required for project management; $\mathrm{Z}$ - project documentation; $\mathrm{R}$ - project resources; $\mathrm{U}$ - instruments required for a project; $\mathrm{M}$ - permanent organisation.

Definition 2. The stochastic function $\left(\xi_{\mathrm{B}}^{\mathrm{Y}}(\ldots)\right)$, which forms the supportive subsystems (support types) in the project management system, is a function that establishes conditions for the 
efficient work of a project team and forms decisions in terms of project management knowledge areas, which are applied at project organisation, planning, realisation and control.

Under the same conditions (parameters $\mathrm{O}^{\mathrm{Y}}, \mathrm{Z}, \mathrm{D}, \mathrm{R}, \mathrm{U}, \mathrm{M}$ ) support types can be realised differently depending on the conditions of project realization, the vision of project team and senior management of the company. For example, project planning instruments, facilities, where the project team works, procurement procedure, risk management methods, information system, which supports communication, HR management, quality management standards, regulation on responsibilities of stakeholders, progress reporting regulations etc.

As with the provision of subsystems at the level of product creation, the function of creating subsystems in the management system is realized by the project team and the functional units, knowledge, skills, experience of which determine the construction of these subsystems. The senior management in particular plays an important role in this process as far as the allocation of funds to ensure the activities of management units is their prerogative. Therefore, the processes of ensuring and creating conditions for project management are stochastic.

\section{3. Processes of project content definition}

Definition 3. The stochastic function of project content definition $\left(\xi_{\mathrm{D}}^{\mathrm{Y}}(\ldots)\right)$ is focused on the development of the statement of work, which is to be done in the project, and provides the description of the work parameters (duration, resources, conditions under which the work can be done, instruments etc).

Stochastic function is described by the formula:

$$
\mathrm{D}=\xi_{\mathrm{D}}^{\mathrm{Y}}\left(\mathrm{Z}, \mathrm{O}^{\mathrm{Y}}, \mathrm{R}^{\mathrm{T}}\right)
$$

where D - project works; $\xi_{\mathrm{D}}^{\mathrm{Y}}(\ldots)$ - stochastic function, which defines project works; $\mathrm{Z}$ - documentation; $\mathrm{R}^{\mathrm{T}}$ - workforce.

On the one hand, projects are determined by documentation. The function of displaying the documentation in the project content could be considered deterministic. Nevertheless, the process of determining content is stochastic, since it is influenced by the knowledge and experience of the workforce involved in the project management. In addition, the organizational structure itself or, more precisely, the functional division of the roles of the project team are affected. Depending on the roles assigned to team members, documents are maintained in order to determine the content of the project. Moreover, this involves the experience of those managers and specialists who perform different roles. In most cases, this process does not concern the question whether to conduct a work, as far as the documentation clearly defines it. In this case, it is important to define what level of works should be presented in the plan. The works can be detailed to such extent that project would contain over 1000 works or, by contrast, they could be consolidated so that the project would contain less than 50 works. It can be described only by a stochastic function, depending on the documentation, experience of the workforce and the distribution of roles in the organizational structure.

\section{4. Processes of defining the resources required for project works}

The processes of defining the resources required for project works are by their nature the processes of project management. They are the framework for defining the required resources and their amounts. These processes are based on the documentation. In the case of geological projects, the types of resources, indicated in the documentation, do not define the name of a resource or an instrument and their parameters. It is clear, that a project developer might not know what instrument will be used in a work. Instruments, which already belong to the company and are free at the moment of their use, are usually used. Therefore, this function is stochastic and can be described in the following way:

$$
\mathrm{R}=\xi_{\mathrm{R}}^{\mathrm{Y}}\left(\mathrm{Z}, \mathrm{D}, \mathrm{U}^{\mathrm{L}}, \mathrm{V}^{\mathrm{Y}}\right)
$$


where $\xi_{R}^{\mathrm{Y}}(\ldots)$ - stochastic function, which defines the required resources; $\mathrm{V}^{\mathrm{Y}}$ - influences on the project team, which define the availability of resources; $\mathrm{R}$ - resources, required for the development of project product.

Definition 4. The stochastic function of defining the project resources $\left(\xi_{R}^{\mathrm{Y}}(\ldots)\right)$ is aimed at developing the list of resources required for project realization and dividing the resources between the project works.

The required resources for different organisations are not the same under different conditions of project realisation due to the availability or lack of some resources.

The project team realises this stochastic function during project planning.

\section{5. Processes of project planning}

Definition 5. Stochastic function of project planning $\left(\xi_{\Psi}^{Y}(\ldots)\right)$ is a function for defining the procedures and period of execution of works.

It is described by the formula:

$$
\Psi=\xi_{\Psi}^{\mathrm{Y}}\left(\mathrm{Z}, \mathrm{D}, \mathrm{R}, \mathrm{U}^{\mathrm{L}}, \mathrm{V}^{\mathrm{Y}}, \mathrm{B}^{\mathrm{Y}}\right)
$$

where $\Psi$ - project plan; $\xi_{\Psi}^{\mathrm{Y}}(\ldots)$ - stochastic function, which defines project plan.

Project planning process can be considered as stochastic, since it is influenced by knowledge and experience of people involved in project management and external influences (for example, influence of operators, senior management etc.). In addition, project planning is always creative in terms of defining the net model, works duration (a list of works and resources is also developed by the abovementioned stochastic processes). The function of project planning is implemented by the project team, knowledge, skills, experience of which determines the nature of the decisions taken. The project team through discussions and evaluating different options defines whether the plan will cover the whole project or a separate phase thereof. These decisions are impossible to predict in advance. For the same inputs, the plan might be different.

\section{6. Processes of influencing project contractors}

The contractors are influenced by management decisions, based on project plans. The process of influencing project contractors is the action of notifying the contractors of the work plan and resources. The contractors are engaged in the planning process in order to provide that the result of such influence is predictable. These processes define influences on work force. Influences of the same plan could be different as far as they are defined by the attitude of functional managers to the project, especially since different contractors can have different motivation to conduct the project. Therefore, this process is unequivocally stochastic:

$$
\mathrm{W}^{\Pi}=\xi_{\mathrm{W}}^{\mathrm{Y}}\left(\mathrm{Z}, \Psi, \mathrm{B}^{\mathrm{Y}}\right),
$$

where $\xi_{\mathrm{V}}^{\mathrm{L}}(\ldots)$ - stochastic function, which defines the influences on the contractors (work force) at the moment; $\mathrm{W}^{\Pi}$ - project management decisions at the moment.

Definition 6. The stochastic function $\left(\xi_{\mathrm{V}}^{\mathrm{L}}(\ldots)\right)$ impacts the functional management (project contractors) and is used for motivating the contractors to execute the project plan and fulfil the conditions of the utilisation of resources. These influences should provide for carrying out the decisions taken at the level of the project team.

The stochasticity of such processes is also defined by the ability of the team members to provide the contractors with the necessary information in the understandable way. The response of the team to the influences will be predominantly stochastic, since it is defined by the knowledge, skills and experience of the project contractors. The project team and the contractors usually understand the task in their own way. It requires the establishment of clear rules of project communication. The types of project management support contribute to it. 
The stochastic nature of notifying of the project plan depends on the different ways and time of notifying, irrespective of the automation of the whole work plan or the operative plan, the development of the responsibility matrix of each work or the whole project etc. [12].

The described process is fully and entirely the result of the scientific work of the authors of the article.

\section{Results}

This research suggests a project management approach, based on the focus on the project product, and project management as stochastic processes, based on stochastic functions. It is demonstrated that stochastic function values, which underlie the stochastic processes, are formed by the intellectual instruments of those involved in the project and are developed on the basis of their knowledge and skills. The latter, in turn, are the result of studying and practical work on the project. Therefore, it is difficult to predict decisions and actions of managers and contractors, even if internal and external influences on them are specified. Then, any decisions or actions of such persons with regard to the external observer are described by stochastic functions.

The processes of stochastic project management are outlined and formally presented. These are the processes of project management organisation, the processes of project management support, processes of project content definition, processes of defining the resources, required for the project works, processes of project planning, processes of influence on contractors of actions (works).

\section{Discussion}

Project management systems developed on classical project management standards [1] for managing innovative projects in a constantly changing environment. For reaction to any changes, a rather complex system of processes is lined up. This concerns both the management of individual projects and the management of a portfolio of projects [2]. Therefore, to manage innovative projects in a dynamic environment, their own approaches and methods should be developed.

Classical methods and models of project management have proven themselves in the implementation of large projects with low dynamics of change [3]. But the complexity of the processes and many regulatory documents make these processes not effective when implementing projects with many changes.

The results of the research complement the existing project management processes. The stochastic project management are used in the management of projects with a high degree of uncertainty.

The implementation of stochastic management processes allows to take an informed decision in a timely manner when realising the projects with a high degree of uncertainty. The use of stochastic processes requires the well-timed information support.

A project management system, based on the proposed groups of stochastic project management processes, will allow you to make informed decisions quickly. The analysis and description of the support processes proposed in the article will allow developing a project management system taking into account changes in the external environment.

It is planned to develop in the further research the instruments of information support of the realisation of stochastic processes, discussed in this research.

\section{Conclusions}

1. Six groups of project management processes under stochastic control are defined. These groups include processes not only for managing the creation of a project's product, but also for processes of project management and supporting processes.

2. A mathematical description of the processes within each group is presented. The elements necessary for the implementation of various types of processes are identified and described.

3. The definitions and descriptions of the working conditions of each group of processes are given. The processes of the six groups complement each other when working within a single project management system. 


\section{References}

[1] A Guide to the Project Management Body of Knowledge (PMBOK® Guide) Ed. 5 (2013). Project Management Institute, 590.

[2] Kerzner, H. (2009). Project Management: A Systems Approach to Planning, Scheduling, and Controlling. Ed. 10. New Jersey: Wiley, 1120.

[3] P2M «Program \& Project Management for Enterprise Innovation» (2016). Project Management Association of Japan. Available at: http://www.pmaj.or.jp/ENG/p2m/p2m_guide/p2m_guide.html

[4] Aaltonen, K., Kujala, J. (2010). A project lifecycle perspective on stakeholder influence strategies in global projects. Scandinavian Journal of Management, 26 (4), 381-397. doi: http://doi.org/10.1016/ j.scaman.2010.09.001

[5] Dehmer, J., Niemann, J. (2017). Value chain management through cloud-based platforms. Procedia - Social and Behavioral Sciences Volume 74, 29 March 2013, Pages 61-70. doi: https://doi.org/10.1016/ j.sbspro.2018.03.021

[6] The Standard for Portfolio Management Ed. 3 (2013). Project Management Institute, 189.

[7] Teslya, Yu., Khlevna, Yu., Yehorchenkova, N. (2016). Knowledge management in the meta-metodology of project planning. Project management and production development, 4 (60), 53-61.

[8] Teslya, Yu. (2010). Introduction to the nature informatics. Kyiv: Maklaut, 256.

[9] Teslya, Yu., Kontsevych, V. (2013). Enhancement of project quality on the basis of introformational method of proactive human resources management. Project management and production development, $1(45), 83-88$.

[10] Timinsky, A., Oberemok, I., Oberemok, N. (2017). Development of methodology of efficiency estimation of management technology of project-oriented organizations. Technology Audit and Production Reserves, 2 (2 (34)), 24-29. doi: http://doi.org/10.15587/2312-8372.2017.100213

[11] Oberemok, I., Oberemok, N. (2017). Development of mathematical model of decision making based on analysis of values of stakeholders. Technology Audit and Production Reserves, 1 (2 (33)), 13-18. doi: http://doi.org/10.15587/2312-8372.2017.93461

[12] Zatserkovnyi, V., Oberemok, I., Oberemok, N., Yehorchenkova, N. (2016). Integration of project management processes at the planning stage to the corporate business processes. Technology Audit and Production Reserves, 6 (1 (32)), 35-42. doi: http://doi.org/10.15587/2312-8372.2016.86176 